psychiatric qualifications, links with, and services for, overseas members, and psychiatric training overseas. It is hoped that there will be a positive response to these proposals, particularly from members overseas.

Representatives of the College and the Welsh Office met in November to discuss the development of psychiatric services for the mentally handicapped in Wales. The Welsh Office has indicated that it will take into account the College's recommendations concerning provisions for this group.

The College held a briefing session for the Press on 19 January, to explain the reasons for its support for the 28 week time limit for therapeutic abortion, particularly in the case of mentally handicapped women.

The College has also submitted evidence on a number of issues currently being considered by the Home Office: these included the Review of the Parole System, amendments to the Liquor Licensing Bill, in respect of the law affecting the sale of liquor to underage persons, and the review of the Law Affecting Amusement Machines.

A College Statement on Benzodiazepines and Dependence, containing useful guidance on indications for use and possible effects, and prescribing, has been approved for publication in the Bulletin. The Statement has been welcomed by the DHSS, and its recommendations are being implemented.

I am pleased to report that Council has elected Dr D. Dick to serve as Vice-President for the year 1987/88.

Professor. R. G. Priest

\title{
Cuts in Mental Health Budgets
}

During discussions on financial cuts to the Mental Health Services I have asked Divisions, Sections and Groups for evidence of cuts to be sent to the College. The Editors have suggested that, to help members to monitor the continuing financial situation, I should explain here the nature of the various financial pressures that are exerted.

Loss of finance can come about in three ways:

(1) Funds arising from closure of run-down mental hospitals should be put into the mental health budget. We have had a ministerial undertaking on this point. Unfortunately, it seems that this does not always happen, and it is difficult to keep track of since one does not always know when such funds have been put into the District budget. Our colleagues in the DHSS would regard this as a very serious deviation of funds.

(2) The mental health budget is set in a District for one year, but the mental health budget in the following year may be cut or may not make full allowance for inflation and so on. If it is possible to have sight of the mental health budget then this is possible to identify. It is important to note details of any cuts both in absolute terms (e.g. $f 1 M)$ and in relative terms (e.g. $7 \frac{1}{2} \%$ of the total mental health budget), and in either case it is helpful to have a note of the total mental health budget Other figures which should be useful, though less crucial, would be the total District budget and the cuts made in the total District budget.

(3) Claw-back of unspent money is common. Where a budget has been set for a year but money has not been spent (e.g. because of difficulty in recruitment of nurses), the unspent money may be clawed back for use to prop up overspending in other specialties.

I have listed these in order of the seriousness with which they might be regarded.

We have sent off evidence of cuts to the DHSS but it is important to continue to be on the alert for further encroachment.

Professor R. G. Priest Registrar 